\title{
Settlement Risk under Gross and Net Settlement *
}

\author{
August, 1999 \\ Charles M. Kahn \\ Department of Finance \\ University of Illinois \\ James McAndrews \\ Research Department \\ Federal Reserve Bank of New York \\ William Roberds \\ Research Department \\ Federal Reserve Bank of Atlanta
}

\begin{abstract}
Previous comparative analyses of gross and net settlement have focused on the credit risk of the central counterparty in net settlement arrangements, and on the incentives for participants to alter the risk of the portfolio under net settlement. By modeling the trading economy that generates the demand for payment services, we are able to show some largely unexplored advantages of net settlement. We find that net settlement systems avoid certain gridlock situations, which may arise in gross settlement in the absence of delivery versus payment requirements. In addition, net settlement can economize on collateral requirements and avoid trading delays.
\end{abstract}

JEL Fields: E58, G21, G28

Keywords: clearing, settlement, settlement risk

\footnotetext{
* Address correspondence to: William Roberds, Research Department, Federal Reserve Bank of Atlanta, 104 Marietta Street N.W., Atlanta, GA 30303-2713, telephone: (404)521-8970, e-mail: william.roberds@atl.frb.org. This paper was written while the third author was a visiting scholar at the Institute for Monetary and Economic Studies at the Bank of Japan. The views expressed in this paper are those of the author and not the Federal Reserve Banks of Atlanta or New York, the Federal Reserve System, or the Bank of Japan.
} 


\section{INTRODUCTION}

In many cases summary measures work as well as the full details. Rather than retaining the details of every transaction that has taken place, it is sufficient to keep track of a summary measure - the running tab - and handle all subsequent relations based on this summary information. This basic insight underlies "net settlement."

The process of netting obligations is essentially the same, whether accounts are handled by a barkeeper or by a central bank. In either case, the job of the manager of the payments system is to keep tabs, ensuring that the participants pay neither too much nor too little. For example, suppose the plumber, a regular patron at the bar, is called in to make a repair there. It makes sense to make an adjustment on her running tab, rather than to go through the bother of finding the cash to make a payment that will only be reversed later that evening. Similarly, it saves time and bother for the participants in a payment system only to be assessed the net amounts that are due.

Thus it has long been recognized that, whenever the process of transmitting a payment is expensive, netting arrangements provide economies. On the other hand, it has come to be recognized as well that netting arrangements can provide a variety of disincentives to proper behavior. The plumber may run up a large tab and then skip town. In the case of central banks, previous comparative analyses of gross and net settlement arrangements have focused on the credit risk of the central counterparty in net settlement arrangements (see e.g., Bank for International Settlements, 1990) and on the incentives for participants to alter the risk of their portfolio under net settlement (Kahn and Roberds, 1998a). This work has therefore tended to emphasize the disadvantages of netting arrangements relative to gross settlement arrangements with regard to participant incentives. 
However, most previous analyses have implicitly assumed a "delivery-versuspayment" (DVP) gross settlement system - that is, a system in which the underlying trade occurs at the same time as the settlement: the plumber pays for the drink at the instant that she buys it. In particular, analyses have typically ignored the underlying trades, which in effect assumes that they are made when payment is made.

In this paper we compare the incentives for strategic default in net settlement systems to those in gross settlement systems with and without DVP. We find that net settlement has some previously unexplored advantages. Net settlement can avoid delays in trading that occur in gross settlement systems. In particular, net settlement systems avoid certain "gridlock" situations, where trading would break down entirely in gross settlement systems that do not use DVP. In some situations, gross settlement can avoid gridlock, but only by using potentially costly collateral. These considerations are important in designing effective payment systems. ${ }^{1}$

The modeling approach we use is one of incomplete contract enforcement. The usefulness of this approach lies partly in its realism. When payments are not settled at the instant of incurring an obligation, counterparty risk arises in the interaction between the debtor and the creditor (and other parties in the system) in the interim before settlement. In a world of complete contracts these interactions would be governed by a customized contract that fully addresses the set of interacting contingencies of the underlying trades. In the rapid working of day-to-day commerce, however, customizing contracts for each trade would be prohibitively costly. Instead, the obligations created by rapid-fire trading are governed by standard legal contracts, which create an intricate ordering and reordering of seniority and priority of debts during the course of trade. Thus the incentives of the agents in the model will depend not only on 
the rules of the payments systems but the general legal rules for default and bankruptcy. In describing the effects of various modifications of the payments system we will hold these aspects of the legal structure constant. An advantage of our analysis is that it makes this dependence on the legal system explicit, and allows us to consider, in a rudimentary way at least, the effects of changes in the bankruptcy laws on the relative efficiency of various payment arrangements.

The fundamental problem of a payment system is whether payment will actually occur and the most basic concern should therefore be the extent to which the rules of the payment system encourage or discourage the making of payments. In our model we utilize the idea of strategic default (developed in Kahn and Roberds 1998a) as the basic incentive problem. Strategic default has the virtue of simplicity, facilitating analysis, but it also is a natural proxy for other forms of incentive problems. The consequence of changes in the likelihood of default will be a change in the willingness of parties to engage in trade. Thus the payments system arrangements in our model's financial sector will have welfare consequences through their effects on the model's real sector.

\section{The Model Environment}

The economy is populated with a large number of risk-neutral agents known as "banks." Initially there will be three time periods, $t=0,1,2$, which span a single trading day. A bank's objective is to maximize its consumption in period $t=2$. There are three types of goods: customized intermediate goods of many varieties, a final good, and a third storable good "manna" which will be used to facilitate payments.

\footnotetext{
${ }^{1}$ Our results on net settlement are related to results obtained in other studies. Below, we compare our findings to those in the literature.
} 
(Manna can be thought of as incoming funds transfers to the bank, whose timing is exogenous). Each type of good has distinguishing physical and legal characteristics.

Only the final good can be consumed. No bank's endowment includes the final good. However, all banks are endowed in period $t=0$ with one indivisible unit of an intermediate good, which can be used to produce the final good in period $t=2$. In order for banks to have an incentive to trade, production of the final good from intermediate goods will involve a "credit chain," as in Kiyotaki and Moore (1997). That is, banks are divided up into $I$ types, where $I>2$ and there are an equal number of banks of each type. For convenience, we will sometimes refer to a representative bank of type $i$, where $i=1, \ldots, I$, as "bank $i$ " or simply " $i$." To produce a final good, bank $i$ requires the input at the beginning of period 2 of the customized intermediate good initially held by bank $i-1(\bmod I)$. Banks can costlessly deliver their customized intermediate good in period $t=1$. In production, one unit of the appropriate customized intermediate good yields $F>1$ units of the final good, and the intermediate good is destroyed in the process. If the intermediate good is not put to its customized use, then it has a salvage value $C<1$ in terms of the final good.

There is a third type of good, manna. All banks are endowed with $M$ units of manna, which arrives as of the beginning of period $t=2$. Like the intermediate goods, manna can be used to produce the final good. However, manna differs from the intermediate goods in two respects. First, one unit of manna yields exactly one unit of the final good, and second, manna is not customized, so that its value is the same to all banks.

Since the focus of our analysis is interbank payment systems, we will interpret agents' trading in intermediate goods as a proxy for any trading of financial claims that gives rise to interbank obligations. The level of abstraction is such that the model 
does not distinguish between trades for customers and trades for the banks' own account. Settlement of obligations by transferring the final good will correspond to settlement in central bank funds, and the appearance of manna endowments will correspond to anticipated, exogenous incoming funds transfers.

In addition to their physical distinctions, different goods will have different legal characteristics according to whether they are attachable in bankruptcy. Suppose that a bank defaults on a commitment and is forced into bankruptcy (in a modern setting, it would be closed down by a regulator). If the bank's attachable assets are $A$ and its obligations to creditors are $O$, then payoffs to the bankrupt and the creditor will be respectively

$$
\begin{aligned}
& \max \{(\alpha+\beta) A-O, \alpha A\} \\
& \min \{O, \beta A\}
\end{aligned}
$$

where $\alpha$ and $\beta$ are positive fractions such that $\alpha+\beta<1$. Thus, in case of default, attachable goods are subject to partial seizure by creditors and are also subject to decay. With respect to the three types of goods, we assume that final goods and intermediate goods are always attachable. We will compare situations where manna is or is not attachable.

The motivation for bankruptcy rules (1) and (2) is that in the case of defaults, claims of "outside" creditors such as a bank's trading counterparties may have less than absolute priority, particularly when the bank is highly leveraged. In such cases, a default will diminish the value of the bank's assets. Also, if a bank thinks that it will default, it may find ways, depending on the legal regime, of redirecting an incoming transfer (i.e., its manna endowment) so that it is not attachable in bankruptcy. 


\section{DECENTRALIZED TRADING UNDER GROSS SETTLEMENT}

In this environment, there is one "round" of decentralized trading. In period $t=0$, banks seek out trading partners in order to obtain the intermediate goods necessary for production. Each bank $i$ enters into a contract to supply bank $i+1$ with an intermediate good in period $t=1$, in return for some payment in the final good at the end of period $t=2$. In addition, bank $i$ obtains a commitment from a bank $i-1$ to provide bank $i$ with an intermediate good, also in return for a later payment of the final good. In both cases the size of the future payment is determined by a bilateral bargaining process, in which both parties possess some bargaining power. Thus, the payment divides the surplus between intermediate good producer and final good producer, with each receiving a strictly positive share, implying $C<P<F$, where $P$ is the going unit price of an intermediate good in terms of final goods, i.e., $P$ is the promised payment from one bank to another. ${ }^{2}$

In period $t=1$, banks customize their intermediate goods, and deliver these goods to the bank that will use them to produce the final good. In period $t=2$, after banks receive their manna endowments, the final good is produced, and barring default, creditors are paid. In each period, all participants have full information about the actions taken by all other participants in previous periods.

Payments take place according to the rules of "the payment system." The first type of payment system we consider will operate under real-time gross settlement, or in this section simply "gross settlement," as there is only one round of trading. In the model environment we interpret "gross settlement" to mean that for payment to occur, banks must actually deliver the payment (in final goods) to their creditors.

\footnotetext{
${ }^{2}$ We exclude the endpoints in order to exclude nuisance (i.e., mixed strategy) equilibria in which banks are indifferent between trading or not trading. The details of the bargaining process are left unspecified.
} 
A bank's strategy $\sigma$ over the trading day is therefore given by $\sigma=(\tau, d, s)$, where $\tau$ represents the bank's trading decision at $t=0, d$ represents its delivery decision at $t=1$, and $s$ represents its settlement decision at $t=2$. The trading decision has two components, i.e., $\tau=\left(\tau_{D}, \tau_{S}\right)$ where $\tau_{D}$ represents the bank's decision whether to request delivery of an intermediate good at the going price $P$, and $\tau_{S}$ represents the bank's decision whether to offer to supply an intermediate good at the going price. ${ }^{3}$ If bank $i$ commits to supply at $t=0$, (that is, if it makes an offer to supply bank $i+1$ while $i+1$ simultaneously makes a request from bank $i$ ), then $d$ represents the bank's decision to either deliver or not, i.e., whether to honor its contractual obligation at $t=1$. If the bank contracts for delivery at $t=0$, and delivery occurs at $t=1$, then $s$ represents the banks decision whether to settle or default at $t=2$.

Below we will consider symmetric subgame perfect Nash equilibria for this environment. Given the information structure, such equilibria can be easily calculated by working backward period by period through the game. In the analysis that follows we will simultaneously handle the cases where manna is or is not attachable; let the variable $a$ equal 1 if manna is attachable and 0 if it is not. Let $x_{i-1}$ represent the intermediate good delivery of bank $i-1$. Then $i$ 's attachable assets are given by

$$
F x_{i-1}+M a
$$

Now consider the incentives of banks to default in period 3. Say bank $i+1$ supplied intermediate good to bank $i$. If $i$ believes that $i+1$ will default then $i$ will strictly prefer to default in turn iff it enjoys higher consumption as a result of the default, i.e., iff

\footnotetext{
${ }^{3}$ In other words, we omit the bargaining aspect of the game; including it would greatly increase notational complexity without having significant effect on our results. Thus the contracts in this game are promises to pay a fixed amount of final good in return for timely delivery of customized intermediate good.
} 


$$
\alpha\left(F x_{i-1}+M a\right)+(1-a) M>F x_{i-1}+M-P_{i-1}+\beta\left(F x_{i}+M a\right)
$$

Above, $P_{i-1}$ represents the promised payment of $i$ to $i-1$. In words, the LHS of (4) equals

$$
\text { debtor's claim on bank } i+i \text { 's non-attachable assets }
$$

whereas the RHS of (4) equals

$$
\text { value of } i \text { 's assets - payment to } i-1+\text { creditor's claim on } i+1
$$

Note that in (4) we must take some stand on what happens in the case of double defaults, i.e., what happens to creditor's share of a defaulting bank's attachable assets when the creditor is also in default. For tractability, we have adopted the convention that creditor's share vanishes in the case of double defaults; other reasonable assumptions will be messier but should cause no significant change in our results.

Suppose that all banks have decided to trade, have honored their commitment to deliver intermediate goods, and have produced their output of final goods. Under gross settlement, will banks now settle or will they default? In symmetric equilibrium, condition (4) reduces to

$$
P>(1-\alpha+\beta)(F+M a)
$$

Condition (7) guarantees "mutually assured default," i.e., banks will default as long as they believe that other banks, and specifically their debtor, will default.

On the other hand, suppose that bank $i+1$ does not default, in which case $i$ 's attachable assets are

$$
F x_{i-1}+M a+P_{i}
$$

Hence if $i+1$ settles, then $i$ will strictly prefer to settle with $i-1$ if and only if

$$
F x_{i-1}+M a+P_{i}-P_{i-1}>\alpha\left(F x_{i-1}+M a+P_{i}\right)+(1-a) M
$$

provided we are in the case where default would lower $i$ 's payment to $i$-1, i.e., where

$$
P_{i-1}>\beta\left(F x_{i-1}+M a+P_{i}\right)
$$


In symmetric equilibrium, conditions (9) and (10) reduce to

$$
\begin{aligned}
& \left(\frac{1-\alpha}{\alpha}\right)(F+M a)>P \\
& P>\left(\frac{\beta}{1-\beta}\right)(F+M a)
\end{aligned}
$$

If (11) and (12) jointly hold, then "mutually assured settlement" will occur, i.e., all banks will settle as long as they believe that other banks will settle. In the case where (12) is reversed, it can be easily shown that each bank will always have an incentive to settle, if it believes that other banks will settle. Thus (11) alone is sufficient for mutually assured settlement in this case.

In the calculations above, it is possible that either all banks will settle or all banks will default at $t=2$, or both, depending on the size of bankruptcy shares and also on negotiated prices. We will first consider situations where mutually assured default and mutually assured settlement are both possible.

Lemma 1. Sufficient conditions for mutually assured default and mutually assured settlement to hold simultaneously are (a) that banks' attachable manna endowment Ma is zero, (b) that the bankruptcy shares $\alpha$ and $\beta$ satisfy $\beta<\alpha<1 / 2$, and (c) that the surplus from production of the final good is not too large, i.e., F/C is sufficiently close to unity.

Proof: Negotiated prices $P$ fall in the interval $(C, F)$. Thus $(7)$ and $(11)$ are satisfied if

$$
C>(1-\alpha+\beta)(F+M a)
$$

and

$$
\left(\frac{1-\alpha}{\alpha}\right)(F+M a)>F
$$


Conditions (a) and (b) ensure that (14) holds. Conditions (a), (b), and (c) ensure that (13) holds.

Q.E.D.

In Lemma 1, conditions (a) and (c) basically impose limits on banks' wealth, so that under some conditions at least, banks have an interest in default. Condition (b) requires that there be deviations from absolute priority $(\beta<\alpha)$, but that debtors not be able to walk away with too large a share of there assets after a default $(\alpha<1 / 2)$.

Proposition 1. Under conditions (a), (b) and (c) of Lemma 1, under gross settlement there exist two symmetric equilibria:

(a) an equilibrium where all banks deliver intermediate goods and all banks settle in final goods, and

(b) autarky.

The all-deliver, all-settle equilibrium dominates autarky.

Proof: To analyze possible equilibria, we consider the incentives of a bank to deliver its intermediate good in period $t=1$, conditional on other banks having delivered. Suppose that a bank believes that all other banks will settle in period $t=2$, so that under the conditions of Lemma 1, the bank will also settle at $t=2$ as long as it has delivered at $t=1$. We conjecture that there is an equilibrium where all banks deliver their intermediate goods and all banks settle. Suppose that the bank deviates from the conjectured equilibrium, i.e., the bank takes delivery of an intermediate good, but fails to deliver an intermediate good. Under this scenario, the deviating bank will have $F+C$ final goods at the beginning of period $t=2$, but will owe payments of $P>C$. Thus, if the bank settles it will have final goods of in the amount of $F+C-P$ which is less than $F$, which would have been its final goods allocation, had it delivered its 
intermediate good. If it defaults, it retains $\alpha(F+C)<F$ final goods. Hence, the bank has an incentive to deliver its intermediate good if it believes that other banks will deliver. Conditional on settlement occurring at $t=2$, if the bank believes that all banks will deliver at $t=1$, then the bank has an incentive to contract with other banks at $t=0$.

Now consider the bank's incentives if it believes that all other banks will default at $t=2$, after having delivered at $t=1$. Under the conditions of Lemma 1 , if the bank has delivered, it will also default. If the bank knows it is going to default, however, its incentive is to hold the largest possible net position against the other banks, in which case it requests delivery of an intermediate good at $t=0$. However, since all banks anticipate that potential buyers of intermediate goods would take delivery and then default, no bank is willing to make an offer to supply intermediate goods. Therefore, in symmetric equilibrium no trade takes place.

Q.E.D.

Proposition 1 shows that an extreme form of "payments gridlock," can occur under gross settlement. Payments gridlock is manifested by a complete breakdown of trade, as banks attempt to shield themselves from a possible ring of defaults. This problem is a coordination failure, since it is only one of two possible equilibria; normal trade can occur under optimistic expectations.

As noted by Kiyotaki and Moore (1997) and Freixas, Parigi, and Rochet (1999) in similar environments, the possibility of payments gridlock creates a form of pure liquidity risk. Gridlock is not caused by any fundamental uncertainty about the value of banks' investments, but instead results from banks' distrust of their mutual creditworthiness. The threat of default by any one bank can cause a loss in priority of all interbank claims, thereby creating a situation where banks find default to be their best 
option. If banks anticipate this costly outcome, they will extend no intraday credit and no trade will occur.

The problem of gridlock does not arise if the liquidity of banks is backed by governmental safety net, i.e., if the banks in question are "too big to fail." Since in this case the banks are fundamentally solvent, a governmental safety net never bails out any bank and hence incurs no costs, as it simply provides banks reassurance against settlement failures. Clearly, blanket government guarantees of the payment system may be not always be available or desirable. Therefore, we now examine some alternative means of eliminating gridlock equilibria.

Consider a version of this environment where banks have positive manna endowments. For a sufficiently large manna endowment $M$, condition (12) will fail, so that delivering banks will not default as long as their manna endowment is attachable. Indeed the banks collectively would be willing to establish a legal system ex ante in which manna is attachable. If such a system is not established, then by an argument identical to that in proposition 1 , coordination failure remains a possible outcome. These considerations prove:

Proposition 2. Suppose that (b) and (c) of Lemma 1 continue to hold. Then

(a) If banks cannot precommit to making their manna endowment attachable, under gross settlement, both the all-deliver, all-settle equilibrium and autarky are possible;

(b) If banks can precommit to making their manna endowments attachable (for example, as a condition for participation in the payments system), and that endowment is sufficiently large then only the all-deliver, all-settle equilibrium is possible. 
In a gross settlement system, preventing a coordination failure in settlement requires some means by which banks can increase the priority of creditors' claims. One way of doing this is by making a large enough portion of their endowment goods attachable, so that incentives for strategic default are extinguished. In the context of the model, Proposition 2 says that banks can do this, but only if they can somehow commit to making their incoming transfers attachable. If banks must credibly commit to attachability as a condition of payment system participation, banks will anticipate that all payment system participants will deliver intermediate goods and settle in final goods. Hence in this case each bank has an incentive to commit to attachability, since its consumption will be higher by condition (11).

In the case of some traditional "national" payment systems, where all participants are based in one country with a single, central-bank-sponsored wholesale payment system, and where all participants would be subject to the same judicial system in bankruptcy, it may be relatively easy to implement this type of arrangement. In such cases, incoming payments (corresponding to the manna endowments in the model) will typically arrive on the books of the central bank, giving the payment system de facto first claim on all such inflows. In cases where payment system participants are based in different jurisdictions, implementation of such a scheme may be more problematic.

An alternative method of increasing creditors' priority would be to use a collateral facility. To model collateral, we must vary the setup slightly, so that some of each bank's intermediate good endowment can be diverted prior to trading. Trading patterns remain the same as before: a bank can only accommodate one other bank's customization order, i.e., each bank continues to supply at most one other bank with intermediate goods. Suppose that a collateral facility is available and that a fraction $\gamma$ of 
each bank's intermediate good endowment must be deposited with the payment system as collateral, before the supplying bank will deliver its intermediate good. Collateral is only useful if the priority of creditors' claims to collateral is somehow greater than for other assets, so we suppose that absolute priority holds for assets posted as collateral. ${ }^{4}$ In other words, collateral functions in the customary way: if the bank does not default on its settlement obligation, its collateral is returned at the end of the day, but if the bank defaults, the defaulting bank's collateral is set off against its unpaid debt. A unit of the collateral is also worth $C$ to the creditor bank. A collateral facility is therefore an effective way of allowing banks to guarantee creditors' priority. Posting collateral is costly, however, because the payment system does not have access to production technologies, so any returned collateral is only worth its salvage value. Formally, we can show:

Corollary to Proposition 2. Suppose manna is not attachable. If there exists a collateral facility and the collateral requirement satisfies

$$
\frac{\gamma}{1-\gamma}=(\alpha-\beta)\left(\frac{F}{2 C}\right)
$$

then the autarchy equilibrium is eliminated. An all-deliver, all-settle equilibrium remains, but this equilibrium is dominated by the equilibrium in Proposition 2(b). Proof. With a collateral facility, in return for delivery of intermediate good the receiving bank must post $\gamma$ of its own intermediate good as collateral against final payment. In return, it will receive $1-\gamma$ units of customized intermediate good for which it will owe $P(1-\gamma)$ in final goods, where, as before $C<P<F$.

\footnotetext{
${ }^{4}$ Establishing such priority may be difficult in some cases. Under U.S. banking law, for example, it is difficult for a bank to pledge assets to entities other than the Federal Reserve. See the discussion in Goodfriend (1990).
} 
Suppose all banks have entered contracts and delivered intermediate goods. A bank will find it undesirable to default even when and all other banks have decided to default if

$$
\alpha F(1-\gamma)<F(1-\gamma)+\gamma C-P(1-\gamma)+\beta F(1-\gamma)+\gamma C
$$

(Note that we have assumed, as before, that a defaulting bank receives nothing from its creditor, and collateral is worth the salvage value in the hands of any firm. As before, changes to these assumptions will not significantly affect results. Also note that there are two $\gamma C$ terms on the right side of the inequality: one is due to the return of the bank's collateral on repayment; the other to bank's receipt of the collateral of its debtor.) Simplifying, we obtain condition (15). Under this condition, autarchy is not an equilibrium, but always delivering and settling is an equilibrium. Under the always deliver always settle equilibrium, a collateral requirement carries with it an opportunity cost of $(F-C) \gamma$, hence if banks can commit to make their manna attachable, as in Proposition 2(b), this will dominate the use of collateral.

\section{Q.E.D.}

Note that condition (15) will always be satisfied for some $\gamma \in(0,1) .^{5}$

\section{Trading Under Net Settlement}

In the model environment, net settlement means the following. At the end of period $t=2$, the payment system calculates each bank's net payment obligation vis-àvis all other banks. Each bank's original payment obligation is then replaced with a new obligation vis-à-vis the payment system, i.e., the payment system becomes a sub-

\footnotetext{
${ }^{5}$ This modified structure can also be reinterpreted as a simple DVP system; however we defer discussion of this interpretation until the end of section 6 .
} 
stitute counterparty. ${ }^{6}$ Banks in a net debit or due-to position then transfer final goods to the payment system, which in turn transfers these to the banks in a net credit or due-from position. The formal definition of equilibrium remains as above.

A key distinction between net and gross settlement systems is that under net settlement, a default of a net debtor necessarily affects the entire payment system, making normal settlement impossible. Hence, a complete specification of a net settlement system requires some rules for completing (or suspending) settlement and for allocating losses among other banks when a net debtor defaults. We consider two rules that have been employed in real-world net settlement arrangements:

Loss-sharing Rule 1 ("unwinding rule"). If a bank defaults, its transactions are removed from that day's transactions, and net positions are recalculated for the remaining banks, and settlement of the recalculated positions proceeds as in normal settlement.

Loss-sharing Rule 2 (“Lamfalussy rule”). Banks must post collateral as a condition for participation, and share the losses resulting from a default. Specifically, the Lamfalussy rule calls for banks to post at least enough collateral to cover a default by any single member. ${ }^{7}$

The Lamfalussy rule is the rule recommended in the Lamfalussy Report (Bank for International Settlements, 1990), and subsequently implemented over many largevalue payment systems. Before 1990, the unwinding rule was the usual rule for such systems.

\footnotetext{
${ }^{6}$ We restrict our attention to cases where such counterparty substitution is binding. In securities industry parlance this is known as "netting by novation" or "binding payments netting," according to whether both securities (i.e., goods) and funds delivery obligations, or funds obligations only are netted. See e.g., Hanley, McCann, and Moser (1995) or Emmons (1997) for a more extensive discussion of netting agreements.

${ }^{7}$ A complete loss-sharing rule would specify rules for settlement in cases of defaults by more than one member bank. Here, due to the symmetry of the model, we need only consider the situation when a single bank defaults.
} 
Under net settlement, the following result is immediate:

Proposition 3. Under conditions (a), (b) and (c) of Lemma 1, under net settlement only an all-deliver, all-settle equilibrium is possible. Any equilibrium under a Lamfalussy loss-sharing rule is dominated by an equilibrium under an unwinding rule.

Proof: First suppose that the unwinding rule is in effect. Consider the typical bank's settlement decision in period $t=2$, where all banks have delivered their intermediate goods in period $t=1$. Then settlement will always occur since the net position of every bank is zero. In other words, there is no opportunity for strategic default, since there is no obligation to default on.

Now consider the incentives of banks to deliver intermediate goods in period $t=1$. If a bank $i$ fails to deliver in $t=1$ but takes delivery of an intermediate good, then in period $t=2$, bank $i$ has $F+C$ final goods and a net debit position of $P$. As was the case with gross settlement, bank $i$ ends up with $\max \{F+C-P, \alpha(F+C)\}<$ $F$ final goods, whereas if bank $i$ had delivered an intermediate good, it would end up with $F$ final goods. Hence banks have an incentive to deliver at $t=1$, which in turn automatically implies settlement in symmetric equilibrium.

Thus, in period $t=0$, bank $i$ has an incentive to contract with other banks at $t=0$, as long as other banks wish to contract. And since bank $i$ can credibly offer bank $i-1$ a payoff higher than what $i-1$ can achieve in autarky, and vice-versa for banks $i+1$ and $i$, then in equilibrium banks will always trade, deliver and settle.

Finally, implementation of the Lamfalussy rule requires posting of collateral, which results in an opportunity cost to banks. From the discussion above, collateral is not needed guarantee delivery or settlement. Hence, implementation of such a rule also results in delivery and settlement, but at a positive opportunity cost.

Q.E.D. 
Proposition 3 spotlights a key advantage of net settlement over RTGS, which is that net settlement can eliminate gridlock equilibria, without the need for either a system by which banks can make future inflows (manna endowments) attachable, or for a collateral facility. Net settlement is effective because it de facto gives absolute priority to offsetting claims, since such claims are automatically discharged under net settlement rules. $^{8}$

Another noteworthy aspect of net settlement is that a bank's membership in a payment system that settles on a net basis generates a kind of network effect. Consider, for example, a four-bank, four-type version of the model, where the payment system settles on a net basis. The fact that all four banks belong to the system generates benefits for all banks, in the sense that gridlock equilibria are excluded. Hence, a network effect is generated in the usual sense that the social benefit of a bank's membership exceeds the bank's private benefit. ${ }^{9}$ This occurs even though each one of the banks is never a direct counterparty to one of the other banks.

\section{Changes in Bankruptcy Payoffs}

In this section we will investigate the effects of bankruptcy rules on the payments systems we have established. The results shown above were derived for fairly sharp restrictions on model parameters and particularly on the bankruptcy shares $\alpha$ and $\beta$. Lemma 1 requires that these parameters be set in such a way that there are deviations from absolute priority, but Lemma 1 also requires that debtors bear a signifi-

\footnotetext{
${ }^{8}$ It is the legal guarantee of the finality of net settlement which is the key to establishing this priority. The link between finality and priority in net settlement has been noted by many observers. See, for example the discussion in Emmons (1997, pp. 39-41).

${ }^{9}$ See Weinberg (1997) for a general discussion of network effects in payment systems.
} 
cant share of the costs of default. We now consider the effects of variations in these parameters.

It is clear that problems with coordination failures will diminish as creditors' priority increases, i.e., as the debtor's share $\alpha$ is driven to zero and the creditor's share $\beta$ approaches unity. In other words in this simple structure, bankruptcy rules maintaining strict priority encourage settlement.

What about the opposite situation, where enforcement of priority rules is further relaxed? Consider the situation where the value of the creditor's share $\beta$ is quite small (possibly zero) and the value of the debtor's share $\alpha$ approaches unity. As $\alpha$ increases, eventually conditions (7) and (12) will hold, but condition (11) will fail. In words this means that "mutually assured default" is still guaranteed, but that "mutually assured settlement" cannot occur. Hence if all banks deliver at $t=1$, then under gross settlement banks will always find default optimal. "All deliver and all default" is not a symmetric equilibrium, however, so in this case the only possible symmetric equilibrium is autarky. We will denote the region of the $\alpha, \beta$ space where this case occurs (in the absence of attachable manna) as the region of inherent mistrust, since in this case optimistic expectations concerning counterparties' willingness to settle are by themselves insufficient to sustain trade. Likewise, governmental guarantees of settlement would be of little value in this case, as settlement guarantees would not give banks an incentive to supply intermediate goods.

This situation can be rectified if manna endowments are large enough, and if banks have some means of precommitting to make these attachable. A collateral facility may also be effective, but it will require prohibitively high levels of collateral as default incentives grow. In addition to preventing defaults at the settlement stage, the collateral requirement must also address the problem of potential delivery failures. To 
see this, consider the case of a bank that takes delivery of an intermediate good, but that does not deliver. The bank then has $F+C$ final goods and a settlement obligation of $P$. For sufficiently large $\alpha<1$, the bank's payoff from not delivering and defaulting on its settlement obligation, which is $\alpha(F+C)$, must exceed its payoff from delivering and settling, which is $F$. Collateral requirements must be large enough to counteract this incentive.

Proposition 4. Suppose that $\alpha$ and $\beta$ fall in the region of "inherent mistrust." Then, under gross settlement

(a) If banks cannot precommit to making their manna endowments attachable, then autarky prevails;

(b) If banks can precommit to making their manna endowments attachable, then for sufficiently large manna endowments, the all-deliver, all-settle equilibrium prevails.

(c) An all-deliver, all-settle equilibrium is also possible with a collateralization requirement, but the collateral requirement must satisfy conditions (15) and $F(1-\gamma)+C \gamma>\alpha(F+C)(1-\gamma)$ and this equilibrium is dominated by the equilibrium in (b);

Under net settlement, the following hold

(d) Under an unwinding rule, autarky prevails;

(e) Under a Lamfalussy rule, then an all-deliver, all-settle equilibrium occurs if the collateral requirement satisfies condition (17), but this equilibrium is dominated by the equilibrium in (b).

Proof: Parts (a) and (b). By the discussions above, autarky is the only possible equilibrium if there is no manna endowment. If the manna endowment is large enough to 
guarantee that (11) holds when manna is attachable, then (a) and (b) follow by arguments in the proof of Proposition (2).

Part (c). If the collateral requirement satisfies (15), then mutually-assured-default condition (7) is reversed. Note also that for small values of $\beta$, then a collateraladjusted value of mutually-assured-settlement condition (11) is automatically satisfied for $\gamma$ satisfying (15).

Now consider the delivery stage. Suppose that a collateral facility is in place with a collateral requirement $\gamma$, leaving banks $1-\gamma$ intermediate goods with which to trade. If a bank deviates from an equilibrium where all banks deliver and all settle, by taking delivery and not delivering, then at the beginning of period $t=2$ it will have $F(1-\gamma)+C(1-\gamma)$ final goods and a net debit position of $P(1-\gamma) \in$ $(C(1-\gamma), F(1-\gamma))$. If the bank settles it gets $F(1-\gamma)+C-P(1-\gamma)$ which is less than $F(1-\gamma)+C \gamma$, which would have been its final goods allocation, had it delivered its intermediate good. If it defaults, it retains $\alpha(F+C)(1-\gamma)$ final goods, but forfeits its collateral $\gamma$. Thus for a collateral requirement satisfying (17) then the bank will always be better off delivering at $t=1$ than not, and it follows that banks will contract at $t=0$. As in Proposition 3, a collateral requirement implies a positive opportunity cost.

Part (d). To analyze this case under net settlement, we note that condition (15) is irrelevant, since delivering banks automatically settle under net settlement. However, condition (17), and hence a collateral requirement, is necessary in order to give banks an incentive to deliver. Hence an unwinding rule which lacks a collateral requirement cannot work in this case. 
Part (e). From arguments above, if the Lamfalussy collateral requirements satisfy (17), then banks will have an incentive to deliver.

Q.E.D.

Proposition 4 establishes that trade can occur in the case of "inherent mistrust" under either gross or net settlement. As in Proposition 3, gross settlement requires either attachability of banks' manna endowments or the use of a collateral facility. Greater amounts of collateral are required as creditors' priority diminishes, so opportunity costs increase. In the case of net settlement, weakened creditors' priority (relative to Proposition 3) also leads to a greater (positive versus zero) collateral requirement being necessary to ensure settlement. The additional restriction on collateral comes from the possible deviation of defaulting without delivering the intermediate goods, a deviation which was automatically dominated under the assumptions of the earlier theorems.

In the case of inherent mistrust, Proposition 4 suggests that either net or gross settlement may dominate, depending on circumstances. If banks' manna endowments can be made attachable, then gross settlement may be able to support trade without the use of a collateral facility. If collateral must be used, then net settlement will dominate gross: The amount of collateral required under gross settlement is weakly higher than the collateral required under net settlement, since the former collateralization requirement must satisfy both conditions (15) and (17), whereas the latter need satisfy only condition (17). For example, in the extreme case where intermediate good prices approach their upper limit $F(1-\gamma)$, the creditor's bankruptcy share $\beta$ is zero, and the debtor's bankruptcy share $\alpha \uparrow 1$, then condition (15) tends to

$$
\gamma \geq \frac{(F / C)}{2+(F / C)}
$$


which exceeds $1 / 2$ for $F / C$ sufficiently large, whereas (17) tends to

$$
\gamma>\frac{1}{2}
$$

In other words, where the temptation to default is great, a collateral requirement of one-half (plus epsilon) of each bank's endowment will guarantee delivery and settlement under net settlement, whereas a higher collateral requirement will be sometimes be needed under gross settlement.

\section{Multiple Trading Rounds}

We now consider a variation of the model where there is a second round of trading. This modified model will allow us to consider the costs associated with delay in settlement; for a more detailed discussion of these issues see e.g., Kobayakawa (1997), Angelini (1998), or Kahn and Roberds (1998b).

Formally, there are now three additional time periods, i.e., $t=3,4,5$ (see Figure 1 for a schedule of events in the extended model). Banks who have not contracted for delivery of an intermediate good may now do so during period $t=3$. During the period $t=4$, it is possible for banks who have not already delivered intermediate goods to customize and deliver these goods. Production and delivery of the final good (barring default) can now take place during period $t=5$ as well as during $t=2$. Consumption of the final good now occurs at $t=5$. However, production is less efficient during the "afternoon" (in period $t=5$ ) than in the "mornings" (in period $t=2$ ), so one unit of an intermediate good yields only $\delta F$ units of utility, where $F^{-1}<\delta<1$. The intuition is that trades that must be conducted late in the day are somewhat less valuable than if the trades are conducted early on. The presence of the discount factor 
places a lower ceiling on intermediate good prices if trading occurs in the afternoon, in which case $P<\delta F$.

It is now necessary to extend the strategy space to accommodate the additional round of trading. Under a real-time gross settlement system, settlement in the form of final good transfers can occur in either the morning $(t=2)$, or in the afternoon ( $t=5)$. Hence, we redefine $\sigma$ as $\sigma=\left(\tau, d, s, \tau^{\prime}, d^{\prime}, s^{\prime}\right)$, where $\tau, d$, and $s$ are as before. The component $\tau^{\prime}$ represents a bank's decision to contract at $t=3, d^{\prime}$ is its $t=4$ afternoon delivery decision, and $s^{\prime}$ represents the bank's settlement decision at $t=5$. Under the net settlement system, there is only one daily settlement, at $t=5$, i.e., the net settlement system operates as a "delayed net settlement" (DNS) system, so under net settlement $s=0$ automatically. The following result describes symmetric Nash equilibria in the two-round game under gross and net settlement.

Proposition 5. With two rounds of trading, suppose that conditions (b) and (c) of Lemma 1 hold for the case where banks' manna is not attachable. Then under RTGS

(a) The equilibria described in Propositions 1 and 2 are also equilibria in the two-round case.

(b) If there is no precommitment of manna endowments and no collateral facility, an equilibrium can occur where all banks deliver and all banks settle, but with delay.

(c) The delayed equilibrium in (b) is dominated by the all-settle, all-deliver equilibrium without delay. However, the delayed equilibrium dominates autarky.

Under net settlement,

(d) Only the all-deliver, all-settle equilibrium is possible. 
Proof: Parts (a) and (b). Under RTGS with an additional round of trading, it is straightforward to show that the equilibria described in Propositions 1 and 2 are feasible and remain equilibria for the two-round case.

Part (c). Using the same arguments as above, if banks believe that settlement will occur at $t=5$, but not at $t=2$, then they will find it optimal to deliver intermediate goods in period $t=4$, and to contract for delivery in period $t=3$. Because afternoon production is less efficient, however, an equilibrium where all banks deliver and settle in the afternoon will be dominated by the equilibrium where all banks deliver and settle in the morning. Banks would like to try and induce earlier trading by offering their potential suppliers higher prices $(>\delta F)$ at $t=0$. But if the suppliers' belief is that early settlement will not occur, then such an offer is not credible.

Part (d). Now consider net settlement for the case where there is one daily settlement, i.e., at the end of period $t=5$. In this case, there is no delayed equilibrium since banks have an incentive to bid up the price of the intermediate good, so as to obtain it in the morning. In contrast to gross settlement, such bids are credible under net settlement because there is no possibility of mutually assured default at the final stage.

Q.E.D.

Proposition 5 illustrates yet another potential advantage of net settlement over gross, which is that net settlement can eliminate equilibria where fear of default leads to costly delays in trading and settlement. As in Proposition (2), the key feature of net settlement in preventing trading delays is its "built-in" assignment of priority to bank's trading counterparties.

Finally, we note that delay costs would also result if the RTGS system were reconfigured as a "delivery versus payment" (DVP) system. Suppose that the payment system were reconfigured so that intermediate goods could only be bought with other 
goods, not promises to deliver goods at the close of business. Within the context of this model, such activities are simply an alternative interpretation of the collateralized payment arrangements. Under this reinterpretation, banks would then have to purchase one another's intermediate goods with their own intermediate goods, leading to a loss in production, or wait until their manna endowments arrive at $t=2$, again implying a loss in production.

\section{IMPLICATIONS}

The discussion above shows, perhaps surprisingly, that net settlement can offer advantages over gross in terms of reducing defaults. Gridlock equilibria that occur under gross settlement do not occur under net settlement arrangements (Propositions 1 and 3). Net settlement can also eliminate equilibria in which trading is delayed (Proposition 5). In situations where collateral is needed to effect settlement, a net settlement system may require less collateral than does a gross settlement system (Propositions 2, 3, and 4). Gross settlement can be made more efficient if banks can establish a facility for making their incoming payments attachable, but enforcing attachability may be difficult in practice. In some cases (with the exception of the "inherent mistrust" environment of Proposition 4), a government guarantee would be sufficient to effect settlement, but in practice governments may be reluctant to extend blanket guarantees to all payment system participants.

As noted above, in our setup net settlement often dominates because it offers an easy way of enforcing creditors' priority. By substituting each party's original payment obligation with an obligation to a centralized counterparty, .a net settlement system can allow for offsets that could not occur under a decentralized (i.e., gross) 
settlement system. In other words, netting in effect replaces a difficult-to enforce debt obligation with another, inherently more enforceable one.

This view of netting is related to one advanced by Green (1997). In Green's model, debt obligations are ex post either perfectly enforceable or completely unenforceable, according to whether debtor and creditor are spatially separated. Under gross settlement, distortions can result when some creditors become physically separated from their debtors, causing them to have to clear their debt through third parties at less than full value. Green shows that a net settlement system can improve welfare by allowing agents' original obligations to be replaced with a set of (enforceable) net claims. ${ }^{10}$ By contrast, in our model no debt contracts are ruled out a priori, but all contracts are only imperfectly enforceable. The inefficiency of gross settlement stems from either the presence of dominated equilibria (gridlock) or higher shadow costs of debt issue resulting from collateral requirements necessary to preclude such equilibria. As in Green's setup, the efficiency of net settlement stems from the substitution of more enforceable claims held by a central counterparty for a less enforceable set of decentralized claims.

We believe that the capacity of netting to reduce settlement risk is an important factor behind the historical predominance of net settlement arrangements for largevalue transactions. The widespread use of net settlement arrangements among banks dates back at least to the Middle Ages (see DeRoover 1948). In U.S. banking history, net settlement arrangements predominated before the founding of the Federal Reserve (see Cannon 1910) and net settlement arrangements continue to be employed today. The netting of settlement obligations has also been an important component of arrangements for settling trades in many types of financial instruments (see Baer, 
France, and Moser 1995). And as recently as the early 1990s, most large-value payment systems in the developed countries were settling on a net basis (see FolkertsLandau, Garber, and Schoenmaker 1996).

Our analysis has abstracted from some disadvantageous of netting systems that have been modeled elsewhere. A number of papers on net settlement (Angelini and Giannini 1994, Emmons 1995, Schoenmaker 1995, McAndrews and Roberds 1999) emphasize the tendency of netting systems to focus credit risk within a central counterparty. Kahn and Roberds (1998a) show how the presence of a strategic default incentive can lead to an increase credit risk when payments are made in a net settlement system, relative to a gross settlement system that employs DVP. Likewise, Freixas and Parigi (1998) show that net settlement may lead to welfare losses by discouraging early liquidation of insolvent banks. Given these drawbacks, the general integrity of a net settlement system will require the imposition of some risk controls (such as imposing position limits, capital requirements, etc.), plus some agreement for sharing losses among system participants. However, an agreement that spreads losses over participating banks can also dilute banks' incentives for mutual monitoring, potentially leading to moral hazard problems (Rochet and Tirole 1996).

As we have pointed out, net settlement arrangements have been coping with such problems for centuries, through a combination of membership requirements, risk controls such as position limits, and appropriate levels of mutual monitoring. We believe that the advantages of net settlement systems that our analysis of strategic defaults has revealed provides a better understanding of the prevalence of the use of netting systems than earlier work might have suggested.

\footnotetext{
${ }^{10}$ Freeman (1996) shows that the availability of free intraday loans from the central bank will have the same effect as netting.
} 
Both the analysis above and the historical tradition of net settlement clearly run counter to the recent changeover of many large-value systems from net settlement to gross settlement systems. By the end of the year 2000, most large-value payment systems in the developed countries will be operating as RTGS systems. This trend is probably driven by issues that are not included in our model. In particular, some of the impetus for different countries to adopt RTGS systems was to provide a standard interface for possible multicurrency and multicountry settlement arrangements. Furthermore, the cost of operating RTGS systems has probably declined relative to netting systems, as information and communication technologies have improved. Legal enforcement of netting agreements is weak in some countries, putting net settlement at a disadvantage to gross settlement in a way our model does not address. Notwithstanding these reasons for the trend toward RTGS, our analysis leads to the conclusion that one should not interpret this trend as proof that RTGS systems are inherently superior or less risky than netting systems.

Our comparative analysis of RTGS and netting systems suggest that some commonly understood advantages of RTGS systems are only available when DVP is employed. The major advantages of netting are not necessarily its reduced need for liquidity (although one of the advantages we find is the reduced need for collateral in netting systems), as is usually discussed, but its greater facilitation of timely trading, and the reduced incentives participants have to default strategically, in anticipation of others' default. When deciding on the design of a payment system, and choosing between a gross or a net settlement system, these advantages should be understood and balanced against any central-counterparty risk that might arise in a netting system. 


\section{Conclusion}

Our analysis of strategic default in settlement systems has revealed some largely unexplored advantages of net settlement systems. By modeling the trading economy that generates the demand for payment services, we've also been able to draw clear distinctions between gross settlement systems that use delivery versus payment and those that don't do so. Previous comparative analyses of gross and net settlement arrangements have focused on the credit risk of the central counterparty in net settlement arrangements and on the incentives for participants to alter the risk of their portfolio under net settlement. Here we have compared strategic default incentives in net settlement systems and in gross settlement systems with and without DVP. We find that net settlement systems avoid certain "gridlock" situations, which may arise in gross settlement systems in the absence of DVP. In addition, net settlement systems can economize on collateral. Finally, net settlement can avoid delays in trading that can occur in gross settlement systems. Extending this analysis to more complex environments will be the subject of future research. 


\section{Figure 1: TIMING OF EVEnTS In ThE MULTIPLE-Rounds MODEL}

Period 0: Banks endowed with intermediate good

Morning contracting occurs

Period 1: Morning customization of intermediate goods

Delivery of intermediate goods

Period 2: Manna arrives

Morning production of final goods

Morning settlement (optional under RTGS)

Period 3: Afternoon contracting occurs

Period 4: Afternoon customization of intermediate goods

Delivery of intermediate goods

Period 5: Afternoon production of final goods

Final settlement 


\section{REFERENCES}

Angelini, Paolo. "An Analysis of Competitive Externalities in Gross Settlement Systems." Journal of Banking and Finance 22 (1998): 1-18.

Angelini, Paolo and Curzio Giannini. "On the Economics of Interbank Payment Systems.” Economic Notes 23 (1994): 194-215.

Baer, Herbert L., Virginia Grace France, and James T. Moser. "Determination of Collateral Deposits by Bilateral Parties and Clearinghouses," in Proceedings of the 31 Annual Conference on Bank Structure and Competition. Chicago: Federal Reserve Bank of Chicago, 1995.

Bank for International Settlements, Report of the Committee on Interbank Netting Schemes of the Central Banks of the Group of ten Countries. Basle, 1990.

Cannon, James G. "Clearing Houses." Report by the National Monetary Commission to the U.S. Senate, 61st Congress, 2nd session, Doc. 491. Washington: Government Printing Office, 1910.

Emmons, William R. "Interbank Netting Agreements and the Distribution of Bank Default Risk." Federal Reserve Bank of St. Louis Working Paper 95-016A, 1995.

Emmons, William R. "Recent Developments in Wholesale Payments Systems." Federal Reserve Bank of St. Louis Review 79 (November/December 1997): 23-43.

Folkerts-Landau, David, Peter Garber, and Dirk Schoenmaker. "The Reform of Wholesale Payment Systems and Its Impact on Financial Markets." Group of Thirty Occasional Paper 51, 1996.

Freixas, Xavier and Bruno Parigi. "Contagion and Efficiency in Gross and Net Interbank Payment Systems.” Journal of Financial Intermediation 7 (1998): 3-31.

Freixas, Xavier, Bruno Parigi, and Jean-Charles Rochet. "Systemic Risk, Interbank Relations and Liquidity Risk by the Central Bank," in Jun Muranaga (ed.), Risk Measurement and Systemic Risk: Proceedings of a Joint Central Bank Research Conference, Tokyo: Bank of Japan, 1999.

Freeman, Scott. "The Payments System, Liquidity, and Rediscounting." American Economic Review 86 (1996): 1126-38.

Goodfriend, Marvin. "Money, Credit, Banking, and Payment System Policy." In David B. Humphrey (ed.) The U.S. Payments System: Efficiency, Risk, and the Role of the Federal Reserve, Boston: Kluwer Academic Publishers, 1990.

Green, Edward J. "Money and Debt in the Structure of Payments." Bank of Japan Monetary and Economic Studies 15 (1997): 63-87. 
Hanley, William J., Karen McCann and James T. Moser. "Public Benefits and Public Concerns: An Economic Analysis of Regulatory Standards for Clearing Facilities.” Federal Reserve Bank of Chicago Working Paper 95-12, 1995.

Kahn, Charles M. and William Roberds, 1998a, "Payment System Settlement and Bank Incentives.” Review of Financial Studies, 11 (1998a): 845-70.

Kahn, Charles M. and William Roberds. "Real-Time Gross Settlement and the Costs of Immediacy," Federal Reserve Bank of Atlanta Working Paper 98-21, October 1998 b.

Kiyotaki, Nobuhiro and John Moore. "Credit Chains." Mimeo, January 1997.

Kobayakawa, Shuji, 1997, “The Comparative Analysis of Settlement Systems.” Centre for Economic Policy Research Discussion Paper No. 1667.

McAndrews, James and William Roberds. "Payment Intermediation and the Origins of Banking." Mimeo, May 1999.

Schoenmaker, Dirk. "A Comparison of Alternative Interbank Settlement Systems." London School of Economics, Discussion Paper No. 205, 1995.

Weinberg, John A. "The Organization of Private Payment Networks." Federal Reserve Bank of Richmond Economic Quarterly 83(1997): 25-43. 